\title{
A GESTÃO AMBIENTAL EM SISTEMAS E REDES: UMA PERSPECTIVA PARA A EDUCACÃO AMBIENTAL NOS MUNICIPIOS BRASILEIROS
}

\author{
Saulo Cezar Guimarães Farias ${ }^{1}$
}

RESUMO: Este artigo analisa as novas estratégias de organização da gestão ambiental e da promoção da educação ambiental nos municípios brasileiros, baseadas na redistribuição das competências e responsabilidades dessas ações pelos órgãos públicos e privados diretamente ou indiretamente ligados a questão. Pretende também evidenciar 0 papel de instituições não governamentais atuantes no município de Rio das Ostras - RJ que são chamadas a participar desta rede ambiental, promovendo um maior alcance e participação social das ações em prol do meio ambiente.

Palavras-Chave: Educação Ambiental; Descentralização; Políticas Públicas. Conselhos Municipais de Meio Ambiente.

\section{INTRODUÇÃO}

Após muitos anos de formulações de políticas públicas para o meio ambiente os problemas que envolvem essa temática ainda são grandes e apresentam singularidades que necessitam ser aprofundadas. A temática ambiental tem ganhado destaque na produção científica, que encontra nesse campo, um vasto território de análise e discussão.

Vários são os trabalhos que discorrem sobre os problemas encontrados nos ambientes naturais brasileiros, em especial, sobre a utilização dos seus recursos para a geração de lucro, na sua devastação pela especulação imobiliária e na ineficiência das políticas públicas para a universalização da educação ambiental entre outras questões tão importantes.

\footnotetext{
${ }^{1}$ Mestre em Educação e Cultura Contemporânea (UNESA), especialista em Planejamento, Implementação e Gestão de EaD (UFF), graduado em Geografia pela Universidade do Estado do Rio de Janeiro (UERJ). Atualmente é professor de Geografia do Colégio Estadual Aurelino Leal em Niterói - RJ, do Centro Educacional Adventista do Rio de Janeiro e da Escola Municipal Maria Teixeira de Paula em Rio das Ostras - RJ. E-mail: saulocg@bol.com.br.
} 
A partir da segunda metade do século $X X$ as questões ambientais ganharam destaque no cenário mundial com o aparecimento de fenômenos naturais causados pelo desequilíbrio dos ecossistemas do planeta, muitos deles atribuídos ao ser humano que não conservou o patrimônio natural de seus territórios e criaram o sistema industrial capitalista que promovia 0 consumo em massa e utilização de recursos energéticos poluidores.

Conforme os problemas ambientais aconteciam, as nações se reuniam (Tibilisi, 1977, Moscou, 1982, Rio de Janeiro, 1992) com o propósito de discutir soluções para frear a devastação e rever o uso dos recursos naturais, de maneira a evitar que eles se esgotassem e que o seu uso não poluísse o que restava.

Observou-se também que as determinações tomadas nos eventos deveriam ser rapidamente transformadas em projetos de educação ambiental para formar futuras gerações mais preocupadas com o planeta e que pudesse conciliar desenvolvimento com uso consciente do meio natural.

Bem, os anos se passaram, muitas coisas foram feitas em relação aos problemas ambientais e sobre a educação ambiental, entretanto, continuamos preocupados com os rumos que as discussões políticas sobre a utilização dos biomas brasileiros para desenvolvimento de atividades econômicas sobre a quantidade de lixo nas cidades sobre o aquecimento do planeta e sobre a fragilidade da articulação entre propostas e a prática dos projetos de educação ambiental no país.

Devido ao fato constatado, este artigo busca analisar, com base em informações colhidas na pesquisa intitulada A gestão ambiental descentralizada e participativa: um estudo sobre o conselho municipal de meio ambiente de Rio das Ostras - RJ (FARIAS, 2010), a desconcentração da gestão ambiental encontrada por alguns municípios brasileiros no intuito de "amarrar" e articular as várias instâncias municipais e privadas que tratam de questões ambientais no município, para juntas trocarem informações e somarem esforços para promoverem projetos de educação ambiental.

Importante ressaltar que essa articulação, em sistemas de meio ambiente, é um desmembramento dos programas do governo federal para descentralização da gestão ambiental por intermédio do Sistema Nacional de Meio Ambiental - SISNAMA e foi incorporada na lei orgânica de muitas regiões que já usufruem dos benefícios da sua implantação como ocorre no município de Rio das Ostras - RJ.

\section{HISTÓRICO DA EDUCAÇÃO AMBIENTAL E SUAS IMPLICAÇÕES NAS POLÍTICAS PÚBLICAS BRASILEIRAS}

Por mais primitiva que seja uma sociedade humana ela tende a transformar a paisagem natural em seu entorno, quer seja para sua subsistência ou para adaptá-la aos seus propósitos. O uso dos recursos naturais do planeta seguia um ritmo cadenciado pela necessidade por quase

Revbea, Rio Grande, V. 8, № 2:77-92, 2013. 
toda a história da humanidade, até o surgimento do sistema capitalista, onde estes recursos passaram a ser explorados intensamente.

O consumo sem limites e a emissão poluentes no meio ambiente desequilibraram os ecossistemas e a humanidade passou a sofrer consequências de suas ações em forma de fenômenos climáticos catastróficos, poluição dos mananciais de água potável e extinção de seres vivos com exemplo. Vislumbrou-se a necessidade de reverter esse quadro que apontava para um planeta sem condições de assegurar a sobrevivência dos seres humanos.

Para que este cuidado pudesse ser eficiente, as nações começaram a se reunir e na década de 1970, divulgaram os primeiros documentos oficiais contendo estratégias para os países implementarem em seus sistemas educacionais, fomentando a educação ambiental em todos os níveis de ensino, assim como em ambientes informais e não formais, criando uma consciência ambiental nas sociedades.

As conferências internacionais sobre meio ambiente passaram a ser frequentes e a cada encontro eram divulgados dados mais recentes sobre pesquisas que mostravam os danos das atividades humanas nos ecossistemas, assim como os primeiros impactos naturais dessas que acometiam os continentes.

Estes acontecimentos internacionais foram essenciais para 0 amadurecimento da formação de uma consciência ambiental brasileira, agrupando um conjunto de informações sobre os ecossistemas nacionais e dos problemas ambientais que o país estava passando, para a formulação das políticas federais de meio ambiente, e para a criação do Sistema Nacional de Meio Ambiente.

Neste período foi possível perceber o "grande salto" dado rumo a formulação de políticas públicas específicas e na criação de uma legislação ambiental mais eficaz e os desdobramentos destas na gestão ambiental em âmbito Federal e em seus entes menores, passaram a ser gradativamente implementadas. Importante relembrar que as ações para uma maior e melhor gestão ambiental no Brasil praticamente se iniciaram na década de 1970, período muito próximo com o debate mundial sobre o Meio Ambiente fato que mostra o envolvimento do país nestas questões paralelamente aos outros países do mundo.

A estrutura que começava a ser criada já encontrava desafios novos e crescentes, relacionados com o progresso no desenvolvimento industrial do país e pela explosão consumista que o capitalismo incentivava. Esse fato foi indicado como maior responsável pelo uso dos recursos naturais e com isso criticado por todos que passaram a buscar alternativas ao sistema. Segundo Chesnais (2003), a humanidade entrou numa fase da história do capitalismo em que as consequências ambientais da acumulação no quadro da dominação mundial do capital financeiro tendem a materializar-se sob formas extremamente graves e num ritmo que se acelera. 
Loureiro (2008) lembra que as causas da degradação ambiental e da crise na relação sociedade-natureza não surgiram ou são condicionadas apenas de fatores conjunturais e do instinto perverso da humanidade, sua degradação não é consequência apenas do uso indevido dos recursos naturais; mas sim de um conjunto de variáveis interconectas.

No Brasil, os reflexos das atitudes governamentais e das reuniões internacionais sobre o meio ambiente, foram sentidos em atitudes como no fortalecimento do SISNAMA, na criação de um Programa Nacional de Educação Ambiental (PNEA) e em muitas ações que gradativamente tomaram corpo e buscaram atender as necessidades locais em cada região.

A degradação dos ambientes naturais trouxe a tona um novo modelo de educação, a educação ambiental que se mostrou a mais vital formação da consciência de gerações que passariam a conviver em ambientes desgastados pela atividade humana e que pelo resto de sua existência teriam de ser monitorados e cuidados pelos gestores mundiais e pela própria população.

Segundo Pedrini (1997, p.35), a EA no Brasil "não traçou um caminho linear, passou e tem passado muitos percalços para a sua implantação e desenvolvimento no ensino formal, não-formal e informal". O autor comenta que "a trajetória da EA parece coerente no discurso técnico, embora se apóie, por via de regra, numa postura política de Estado Mínimo e submissão da sociedade às barbáries das regras de mercado econômico".

Guimarães (2006) acrescenta ainda que os propósitos da educação ambiental extrapolam os ambientes formais de ensino, espaços que apresentam inúmeras contradições e deficiências muito além da estrutura física, problemas de formação e teórico metodológicos, problemas sociais e políticos entre muitos outros.

Apenas reconhecer a gravidade dos problemas ambientais, como resultado de um processo educativo, pouco avança na construção da sustentabilidade. Sendo assim, a ação que me parece prevalecer ainda nos ambientes educativos restringe-se apenas à difusão da percepção sobre a gravidade dos problemas ambientais e suas consequências para o meio ambiente. Essa perspectiva não é suficiente para uma educação ambiental que se pretenda crítica, capaz de intervir no processo de transformações socioambientais em prol da superação da crise ambiental da atualidade. (GUIMARÃES, 2006, p.15 e 16).

Não são poucas as falhas constatadas na construção de um plano nacional de educação ambiental em suas modalidades (formal, não formal e informal), caso que favorece a falta de uma consciência sobre como cuidar e lidar com os ambientes naturais e como os danos ambientais irá se refletir em problemas para as populações das regiões afetadas e para o país num todo.

Apesar de tudo isso, a Educação Ambiental (EA) pretende promover a compreensão da existência e da importância da interdependência econômica, social, política e ecológica. O ensino de EA formal constitui fundamento imprescindível para a construção de uma sociedade consciente, ativa e Revbea, Rio Grande, V. 8, N²:77-92, 2013. 
preparada para intervir em questões ambientais e promover o desenvolvimento da região mantendo preservados seus recursos naturais (BRASIL, 1999).

\section{A DESCENTRALIZAÇÃO DA GESTÃO AMBIENTAL E OS CONSELHOS DE MEIO AMBIENTE}

Muitos países das Américas e do mundo passaram por um período de consolidação do sistema capitalista em seus territórios na segunda metade do século XX. Alguns precisaram realizar uma profunda reestruturação dos seus sistemas sociais, políticos e econômicos para se adaptarem as exigências do sistema.

Alguns desses países foram tomados por regimes ditatoriais e repressores, com o discurso de afastar a corrupção e morosidade da aplicação dos recursos internacionais cedidos para acelerar o desenvolvimento industrial e resolver seus problemas de infra estrutura. Em virtude dessa situação começaram a surgir movimentos populares e pressão internacional pedindo tempos de maior liberdade e democracia.

O regime militar brasileiro (1964-1985), que se instalou no país para resolver uma gama de problemas, foi acusado de fracassar nos seus objetivos e atrasar o pretendido "salto" que todos almejavam. Iniciava-se um movimento de redemocratização do país culminado com as eleições diretas para presidente da república em 1984.

Vechia (2006, p. 10), destaca que a "redemocratização do Brasil foi reavivada no final da década de 1980 , quando o regime militar se desfazia, e essa aspiração se refletiu na Constituição Federal onde os direitos sociais e econômicos podem ou não vir explícitos em uma constituição". As constituições mais antigas pouco falam de tais direitos explicitamente, as constituições pós Segunda Guerra Mundial é que trazem em seu texto de forma expressa os direitos sociais e econômicos, o que no caso brasileiro, se configura na constituição democratizante de 1988.

Seja como resultado de um grande esforço explícito na Constituição Federal e deliberado pela descentralização de competências e atribuições, seja pela descentralização de recursos a partir de 1988, seja como importante resultado da dinâmica democrática e da maior proximidade dos governos locais com relação às necessidades da população, o fato é que os governos estaduais e, sobretudo os municipais estão promovendo um processo de reforma da ação do Estado na área social, rompendo com algumas das características tradicionais da intervenção estatal no Brasil nessa área (VECHIA, 2006).

Nos municípios, encontraremos os espaços mais próximos dentro da esfera política por onde a participação social poderá se alcançada por meio de sua participação nos conselhos sociais. Estes foram designados pela constituição a se tornar a voz da população no acompanhamento das decisões políticas. A criação destes conselhos, de inspiração constitucional, faria parte 
de um programa de maior autonomia local destes entes numa estratégia do Estado Federal de empurrar seus deveres sociais para a sociedade e outras entidades não-governamentais tendo mais agilidade para conduzir sua economia como queria os organismos internacionais de países capitalistas (GOHN, 2005).

Segundo Souza (2008), o processo de federalização e descentralização da administração pública se materializou no país com o surgimento desordenado de municípios que passaram a ter mais poder e autonomia frente o governo estadual e federal. O autor afirma que a partir da Constituição de 1988 até o ano 2000, a divisão territorial do país foi largamente aprofundada, criando-se cerca de $25 \%$ (1.438) de todos os Municípios atualmente existentes (5.560) e este processo foi resultado de práticas políticodecisórias que se efetivaram a margem de critérios técnicos administrativos que contemplassem a real capacidade de emancipação local.

Este processo de municipalização desordenado serviu para caracterizar a abstinência do Estado da regulação das políticas sociais e após a descentralização, observamos que estas políticas surgiram da manipulação e uso de critérios politiqueiros e serviram para disseminar o clientelismo e empregar políticos, que estariam influenciados e "patrocinados" por terceiros legitimando seus interesses nas regiões que buscaram sua emancipação.

Vale lembrar que, segundo Souza (2003), muitos dos municípios criados, aproximadamente $80 \%$ deles, dependem exclusivamente do Fundo de Participação dos Municípios (FPM) e não apresentam condições sociais, políticas e econômicas para se sustentarem.

Nos municípios os Conselhos de Meio Ambiente atuam conjuntamente com os demais espaços participativos do município para, em áreas específicas, atuarem na solução de problemas ambientais, incentivar projetos sustentáveis e fomentar a educação ambiental que passariam a surgir no território e nos debates locais, envolvendo a sociedade civil para tomar parte de tudo isso.

Os CMMA são instâncias deliberativas voltadas para o exame de projetos do poder executivo e do setor privado que impliquem em problemas na esfera educacional e impactos ambientais, e para a constituição de fóruns de disseminação de informações ou de construção coletiva de conhecimento na área, entre outras funções, prevendo, ainda, a participação da sociedade civil em seu colegiado.

Eles se configuraram, com maior ou menor importância, nos espaços mais democráticos do município para que houvesse uma aproximação da sociedade com as questões ambientais locais. Estes espaços, criados a partir da Constituição Federal de 1988, deveriam ser preenchidos de representantes das camadas da sociedade, do executivo e do setor privado que pudessem estar implicados na resolução de problemas das esferas educacional e ambiental.

orém, essa participação é questionada nos estudos de Souza (2008), Toledo (2007), entre outros, pois a constituição dos CMMA não refletiria Revbea, Rio Grande, V. 8, № 2:77-92, 2013. 
evolução das práticas democráticas, com a representação popular podendo interferir na promoção da justiça ambiental. Aliado a este pressuposto, os CMMA seriam organizações de fachadas e legitimadoras das práticas capitalistas depredadoras e degradadoras do meio ambiente.

Dentre as atribuições delegadas a estes conselhos, destacamos o caráter de promoção participativa nas decisões políticas e na tentativa de transparecer estas decisões, porém, percebemos que nem sempre a descentralização das políticas públicas se configurou em um benefício para a população. Como vimos nos estudos de Souza (2003) e Gohn (2005), as políticas são mal planejadas e as verbas consequentemente são mal aplicadas e desviadas.

Importante ressaltar a importância do conselho como espaço de interface na gestão ambiental municipal, podendo o mesmo atuar nos espaços políticos, em conjunto com empresas privadas e na sociedade, principalmente na formulação de projetos de educação ambiental formais (em conjunto com a secretaria de educação) e não formais (com ONGs, Associações de moradores entre outras).

Toledo (2007) nos lembra que alguns estados brasileiros têm logrado êxito no processo de descentralização da gestão ambiental enquanto outros ainda não conseguem se desvencilhar de uma postura mais conservadora, como o do Estado do Rio de Janeiro que, até a última gestão de governo, optou pela desconcentração da gestão ambiental. Este fator é caracterizado pela falta de capacidade dos municípios em gestão ambiental e ao fortalecimento do SISNAMA.

Contudo, não podemos deixar esquecer que na criação destes conselhos a participação social não foi requerida, ou seja, eles não surgiram de uma demanda da sociedade por maior participação democrática na formulação das políticas públicas, sendo formados verticalmente por iniciativa do Governo Federal simplesmente em observância as leis e não às necessidades de democratização da gestão pública.

E esse fato alerta que, segundo Santos (2001, p. 45), seria provável que os Conselhos se transformassem em "estruturas burocráticas formais, subordinadas às rotinas administrativas das secretarias municipais, no sentido de responder aos procedimentos de aprovação de contratos e prestação de contas exigidas nos convênios estabelecidos com os programas estaduais e federais". Este aspecto também nos remete ao seguinte questionamento: seria possível uma organização social como o CMMA, que é estruturado e organizase a partir de uma formalização do poder público, contrapor a sociedade política e contrariar interesses capitalistas, considerando práticas preservacionistas e conceitos referentes ao desenvolvimento sustentável?

A constituição dos conselhos segue as disposições da PNMA que tem por objetivo a preservação, melhoria e recuperação da qualidade ambiental propícia à vida, visando assegurar no país, condições ao desenvolvimento sócio-econômico, aos interesses da segurança nacional e à proteção da 
dignidade da vida humana, o que é considerado no Art. 129, onde:

Caberá ao Conselho Municipal de Meio Ambiente, órgão deliberativo de representação paritária do Poder Público e da sociedade civil, assegurada á participação de um membro da procuradoria-geral do município, resguardadas outras atribuições estabelecidas em lei, definir, acompanhar, fiscalizar, promover e avaliar políticas, ações, projetos e programas referentes às questões relativas ao meio ambiente (BRASIL, 1981).

Segundo dados mais recentes, retirados da Pesquisa de Informações Básicas do IBGE (2009), contento os resultados das pesquisas realizadas em 2009 sobre a existência e funcionamento dos CMMA (porcentagem total), grande parte dos Conselhos de Meio Ambiente apresentam caráter paritário e consultivo, seguindo esta singularidade outros 2.531 são de caráter deliberativo dando a impressão que as ações dos conselhos cada vez mais se afastam de caráter mais prático e de maior poder decisório do que é levado para deliberações nas reuniões conselhistas, onde aproximadamente $45 \%$ dos conselhos apresentam caráter normativo e fiscalizador, caráter estes que são os responsáveis pela execução das decisões tomadas pelo CMMA.

Observamos também na análise dos dados que dos 3.124 CMMA encontrados, 904 não realizam (no mínimo uma reunião durante doze meses) reuniões frequentes, alguns não as realizam e provavelmente só existem para cumprimento de Lei.

\section{O MODELO INTEGRADO ATRAVÉS DO SIMMA EM RIO DAS OSTRAS}

O Conselho Municipal de Meio Ambiente (CMMA), a Secretaria de Meio Ambiente, Agricultura e Pesca (SEMAP) e o núcleo de EA integram o Sistema Municipal de Meio Ambiente (SIMMA), que compreende um conjunto de órgãos e entidades públicas e privadas integrados para a preservação, conservação, defesa, melhoria, recuperação, controle do meio ambiente e uso adequado dos recursos ambientais no Município (FARIAS, 2010).

O Sistema foi criado na intenção de atrair a relação entre os mais diversos tipos de organizações legalmente representadas nas ações de Meio Ambiente e é gerido pelo Código de Meio Ambiente do município, que destaca suas efetivas funções e atribuições, consoantes o disposto neste Código (RIO DAS OSTRAS, 2008). O SIMMA constitui uma tentativa de estabelecimento de uma rede intersetorial que pretende agregar órgãos e institutos no desenvolvimento de estratégias para disseminar a educação ambiental pelos municípios assim como projetos e ações para recuperação, manutenção e criação de espaços naturais preservados.

Importante ressaltar que a criação e efetivação do SIMMA não é regra na grande maioria dos municípios brasileiros, apesar de sua criação ser uma Revbea, Rio Grande, V. 8, N²:77-92, 2013. 
determinação legal. Alguns não possuem nem o Conselho de Meio Ambiente e legislação específica para as atividades ambientais obrigatórias, como podemos observar na Tabela 1.

Tabela 1 - Municípios, total e com legislação específica para tratar da questão ambiental, segundo as Grandes Regiões e as classes de tamanho da população dos municípios - 2009

\begin{tabular}{|c|c|c|c|c|c|c|c|c|}
\hline \multirow{4}{*}{$\begin{array}{c}\text { Grandes } \\
\text { Regiões } \\
\text { e } \\
\text { classes de } \\
\text { tamanho } \\
\text { da } \\
\text { população } \\
\text { dos } \\
\text { municípios }\end{array}$} & & & \multicolumn{6}{|c|}{ Município } \\
\hline & \multirow{3}{*}{ Total } & \multicolumn{7}{|c|}{ Com legislação específica para tratar da questão ambiental } \\
\hline & & \multirow{2}{*}{ Total } & \multicolumn{6}{|c|}{ Legislação ambiental organizada como } \\
\hline & & & $\begin{array}{c}\text { Capítulo } \\
\text { ou } \\
\text { artigo } \\
\text { na Lei } \\
\text { orgânica }\end{array}$ & $\begin{array}{l}\text { Código } \\
\text { ambiental }\end{array}$ & $\begin{array}{c}\text { Lei de } \\
\text { criação de } \\
\text { Unidades de } \\
\text { conservação }\end{array}$ & $\begin{array}{c}\text { Capítulo } \\
\text { ou } \\
\text { artigo } \\
\text { no } \\
\text { Plano } \\
\text { Diretor }\end{array}$ & $\begin{array}{c}\text { Diversas } \\
\text { leis }\end{array}$ & Outras \\
\hline Brasil & 5565 & 2578 & 964 & 481 & 85 & 256 & 792 & \\
\hline Sudeste & 1668 & 895 & 333 & 112 & 46 & 67 & 337 & \\
\hline
\end{tabular}

Fonte: Elaboração a partir do IBGE, Diretoria de Pesquisas, Coordenação de População e Indicadores Sociais, Pesquisa de Informações Básicas Municipais 2009. Disponível em: http://www.ibge.gov.br/home/estati. shtm. Acesso em 18 maio 2010.

De acordo com os dados da pesquisa sobre informações básicas do IBGE em 2009, dos 2578 municípios existentes no país poucos possuem as leis que garantem o correto tratamento das questões ambientais, ficando o município sem condições de corrigir, punir e orientar as questões ambientais que são levadas aos órgãos responsáveis, não obedecendo ao previsto no SISNAMA.

Dentro dos projetos criados pelo núcleo de Educação Ambiental está a Rede de Educadores Ambientais (REARO). A Rede de Educadores Ambientais de Rio das Ostras foi criada para tratar das questões relativas ao meio ambiente da região, que são discutidas em vários espaços constituídos legalmente: Associações de Moradores, Secretarias da Prefeitura, ONGs, Empresas Privadas e outros que tem relação direta e indireta com os espaços naturais do município.

Existe no município uma união entre segmentos públicos para promoção de projetos de EA, aliando as Secretarias de Meio Ambiente, Agricultura e Pesca, Secretaria de Educação no Núcleo de Educação Ambiental e a Rede de Educadores Ambientais de Rio das Ostras (REARO) 
com sede no parque dos pássaros.

Este espaço reúne os responsáveis pela elaboração, execução e divulgação de propostas para implementar a EA nas escolas e para a sociedade, assim como a realização de palestras para empresas privadas, dando suporte e orientando estas empresas para atuarem no município. Estão em funcionamento, no ano de 2010, inúmeros projetos chamados de Ecoprojetos, Eco-oficinas, eventos e fóruns de EA, atraindo a sociedade civil, participantes de outros Municípios e de outros Estados para as programações.

A REARO promove a realização de projetos e eventos de várias naturezas contando com a participação direta e indireta de diversos segmentos da sociedade civil e das secretarias da prefeitura não deixando de salientar a presença do CMMA dando suporte sempre que necessário for, para que estas ações constituam na formação de uma consciência ambiental na população riostrense. Grande parte destes projetos são realizados dentro das escolas do município (Figura 1 e 2) em conjunto com a Secretaria Municipal de Educação (SEMED), nas salas de aula das turmas de Educação Infantil e Ensino Fundamental, formando os futuros cidadãos que serão responsáveis pela preservação dos ambientes naturais da sua região.
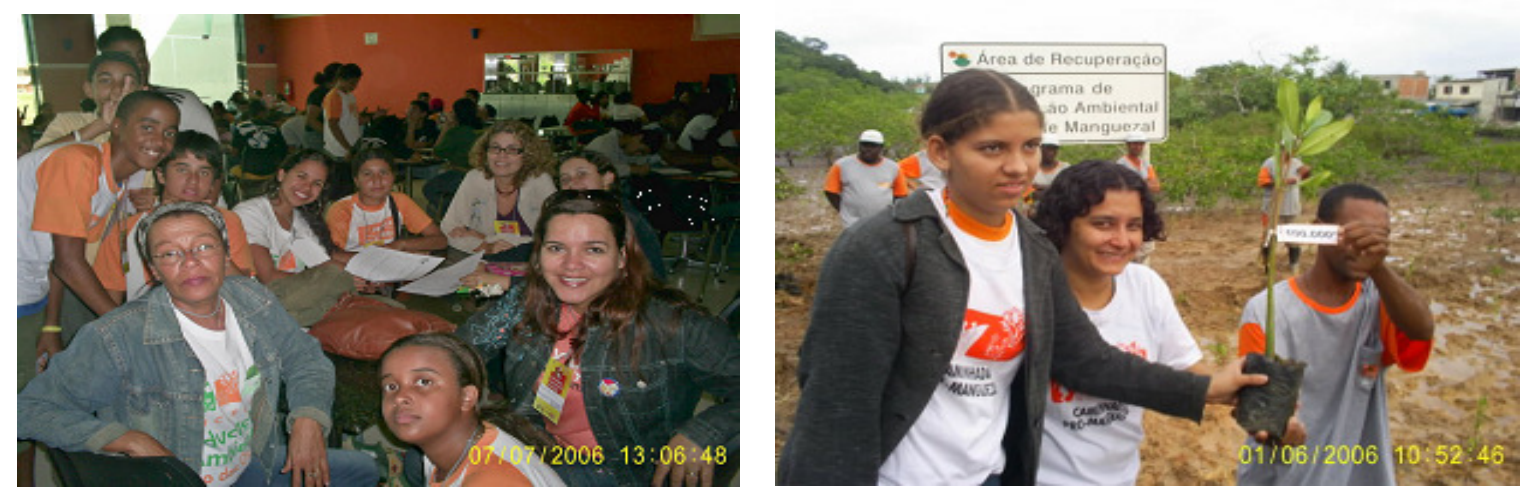

Figuras 1 e 2: ECO Oficinas e Caminhada Pró-Manguezal. Fontes: http://educacao.riodasostras.rj.gov.br/rearo/pdf/ecooficinas.pdf e http://educacao.riodasostras.ri.gov.br/rearo/pdf/caminhapromanguezal.pdf

Em seus Artigos 265 e 266, a Lei Orgânica Municipal (LOM) define que os conselhos, de modo geral, são órgãos de cooperação governamental que têm por finalidade auxiliar a administração no planejamento, execução, fiscalização, controle e na decisão de matérias de sua competência, e preconiza que estes deverão ser regulamentados por leis específicas e com representatividade paritária, respectivamente.

Segundo dados colhidos com as entrevistas e após análise dos questionários respondidos pelos representantes do CMMA de Rio das Ostras e 
pelo secretário de Meio Ambiente do município, algumas questões foram levantadas referentes a administração do CMMA bem como o seu funcionamento e relação com as demais secretarias do município e com os entes estaduais e federais entre outras questões.

$\mathrm{Na}$ assembleia geral das Conferências, alguns diagnósticos são levados para discussão e logo após são confeccionados os relatórios que serão postos em prática nos mandatos subsequentes e na próxima Conferência serão lidas e debatidas as ações realizadas pelo biênio. Segundo o presidente do CMMA:

[...] nós nos preocupamos muito para que nas reuniões sejam elaboradas propostas eficazes e que estas atendam as expectativas reais do município, não "sonhando muito alto" tendo uma satisfação em ver e apresentar resultados reais.

A respeito das Parcerias Público-Privado (PPP), o conselheiro comenta que existem várias ações conjuntas, principalmente na área de Educação Ambiental, pois os recursos públicos para a gestão e os valores recebidos pelos royalties, não tem sido suficientes para suprir as necessidades do município fazendo com que a prefeitura adotasse tais estratégias. $\mathrm{O}$ Conselheiro afirma que:

[...] se dependêssemos somente do dinheiro dos royalties, demoraríamos uns 15 anos para realizar tudo que foi realizado, todas estas obras que você tem visto, foram construídas com o dinheiro da prefeitura que vem do ICMS, royalties e de parceiras com diversas empresas privadas que atuam aqui.

Indagado sobre a existência de diagnósticos socioambientais no município, o conselheiro afirmou que em todas as Conferências de Meio Ambiente realizadas no município, problemas socioambientais são apresentados e discutidos nas plenárias e suas resoluções votadas pela assembléia. Segundo Novicki (2006), o diagnóstico representa uma estratégia para sistematizar a coleta de dados mostrando um quadro das relações entre a sociedade e o ambiente natural, facilitando a formulação de estratégias para resolver o problema.

O presidente do CMMA lembra que um dos primeiros relatórios sobre os problemas sócio ambientais no município foi realizado pela Petrobras. A primeira etapa do diagnóstico (novembro de 2005 a dezembro de 2006) compreendeu um levantamento dos aspectos socioambientais, realizado nos treze municípios que sofrem influência dos empreendimentos relacionados com a exploração do petróleo. O diagnóstico buscou estabelecer parcerias com os municípios, e para isso utilizou-se de um acordo de cooperação técnica assinado por cada município, NUPEM/UFRJ e Petrobras. Ele também acrescenta que; 
[...] na verdade, participação é isto, apresentar os problemas aos conselheiros, a sociedade e juntos tomarmos decisões para resolver os problemas do município, e como este quadro está se aprimorando há vários anos, podemos perceber a maturidade do Conselho partindo para definir resoluções que irão interferir no cotidiano da população.

No projeto acima, foram estabelecidos contatos nos municípios, visitadas escolas, unidades de conservação, ecossistemas e organizações da sociedade civil com o intuito de obter um panorama das ações de EA em cada município e suas principais características, tais como: a realização de projetos, sujeitos envolvidos, potencialidades dos ecossistemas para realização de atividades de EA, conflitos socioambientais existentes, em especial aqueles decorrentes das atividades da Petrobras nos municípios. Além do levantamento dessas informações, durante o diagnóstico foi realizada uma seleção que envolveu técnicos e professores das Secretarias de Educação e Meio Ambiente, para definir os representantes dos municípios que viriam participar do Curso de Formação de Educadores Ambientais.

A Petrobras contribui com a EA por meio do projeto Pólen (Gestão Participativa do Petróleo) promovendo oficinas, projetos e ações direcionadas à população. O Projeto Pólen é fruto de uma união entre o IBAMA e a Petrobras na elaboração de projetos de Educação Ambiental nos municípios em que a empresa atua. Atende condicionantes de licenciamento ambiental e exige que os mesmos tenham foco de sua ação na mitigação dos impactos causados pela Atividade de Produção e Escoamento de Petróleo e Gás Natural, seguindo uma linha traçada pela Coordenação Geral de Educação Ambiental (CGEAM), que prioriza o controle social nesta ação.

Segundo a gestora do projeto Pólen no município, uma das principais ações em benefício da conscientização popular sobre o cuidado com os ambientes do município está na promoção da Educação Ambiental dedicada aos cidadãos, às empresas e aos jovens, se apresentando nos modelos formais (com projetos variados dentro das escolas de educação básica) e não formais com outros muitos projetos elaborados todos os anos pela REARO, pela sociedade civil organizada e por empresas privadas na comunidade.

Analisando os questionários distribuídos aos Conselheiros foi possível observar muitos aspectos interessantes que foram ilustrados nos gráficos. No tocante às competências e atribuições do CMMA, destacamos a sua responsabilidade com o acompanhamento dos projetos de EA (56\%). Foi constatado que o CMMA ao dar apoio, suporte técnico, aparato físico e humano, a fiscalização das atividades de EA tem se mostrado não tão eficiente (69\%), por falta de pessoal e também pelo CMMA dividir esta responsabilidade com outros órgãos no município, o que está ilustrado nos Gráficos 1 e 2.

As questões sobre educação ambiental fazem parte das atividades e discussões das plenárias do CMMA, mas foi observado que o principal órgão

Revbea, Rio Grande, V. 8, N² 2:77-92, 2013. 
de desenvolvimento destas atividades é o NEA, que articula estas ações com outras diversas organizações e instituições públicas e privadas que atuam na região (Petrobras, SEMED, empresas privadas, ONGs, Associações de Moradores, entre outras) disseminando as informações e promovendo projetos, tanto formalmente (escolas) quanto informalmente (espaços comunitários). Outro fato constatado foi que o Conselho realiza periodicamente Grupos de Trabalho (GTs) sobre temas diversos, englobando, assim, a EA nestas instâncias, como ilustrado nos gráficos 3 e 4.

Gráfico 1 e 2 : Acompanhamento das atividades de EA no município e fiscalização das atividades de EA no município

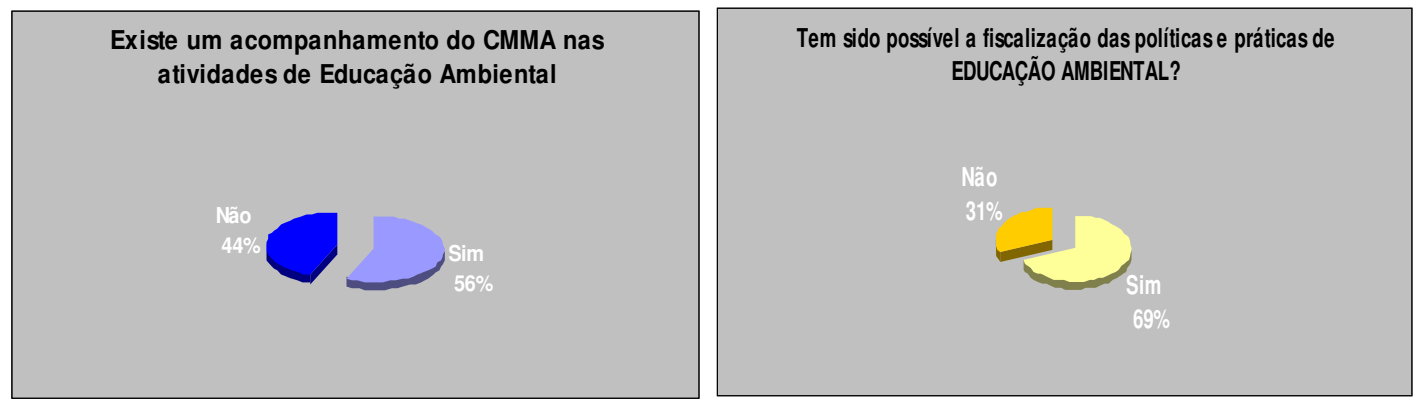

Fonte: Questionário CMMA, 2010.

Gráficos 3 e 4: Sobre as questões de Educação Ambiental discutidas no CMMA e Sobre a interação do CMMA com outros órgãos.

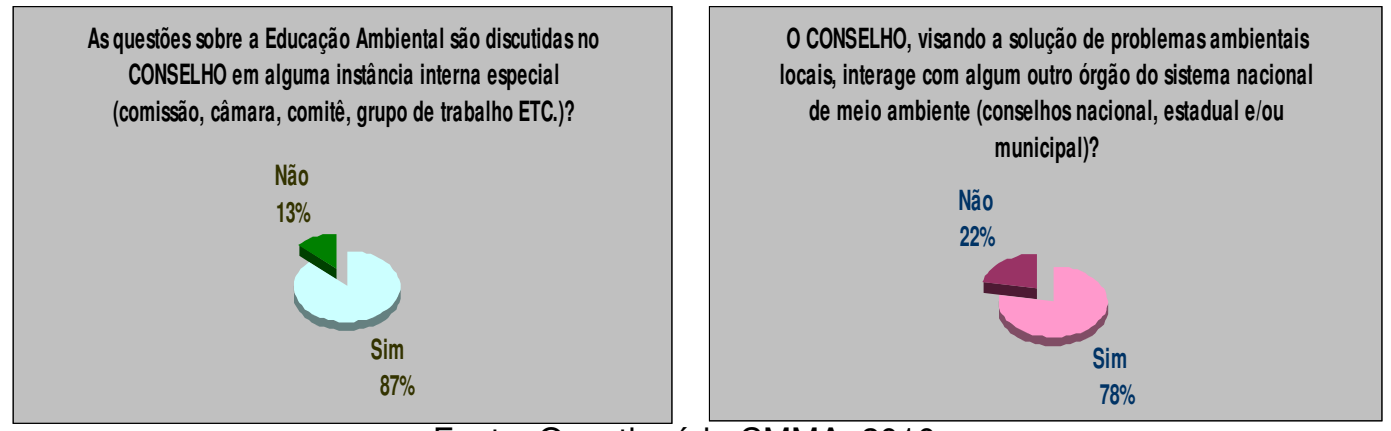

Fonte: Questionário CMMA, 2010.

Um aspecto averiguado e que pode ter considerações relevantes, está relacionado com a interação do CMMA com outros órgãos do Sistema Nacional, na esfera Estadual e Federal. $\mathrm{Na}$ avaliação das respostas, pôde-se observar que $22 \%$ dos conselheiros respondentes desconhecem a relação de algumas atividades do CMMA com estes órgãos por não serem informados. $O$ que se sabe é que periodicamente o Conselho Estadual é consultado pela presidência do Conselho de Rio das Ostras quando uma situação deixa dúvidas ou quando um problema extrapola a competência da Secretaria municipal de Meio Ambiente, e que o CMMA do município interage com outros Conselhos de municípios vizinhos que compartilham de mesmas áreas naturais

Revbea, Rio Grande, V. 8, N²:77-92, 2013. 
comuns e possuem interesses em comum.

Contudo, foi averiguado que em outros municípios que estão criando seus Conselhos, existe uma necessidade de adaptação da legislação ambiental municipal, da estrutura física para fiscalizar as ações do Conselho e da articulação das secretarias, entidades civis e setor público na formulação de projetos de EA adaptando documentos e ações de outros Conselhos Municipais e do Conselho Estadual.

\section{CONSIDERAÇÕES FINAIS}

O município de Rio das Ostras é conhecido por possuir prestígio no Estado como região que investe seus recursos em projetos de Meio Ambiente e em Educação Ambiental, o que realmente foi averiguado, contudo, não foi possível estabelecer a relação entre o montante do capital recebido (impostos, fundos e parcerias para serem usados na gestão ambiental) com a quantidade de projetos, sabendo ao certo se realmente o município administra e investe bem seus recursos financeiros.

A rede de educação ambiental formada com a participação de vários segmentos da sociedade civil (ONGs, Associação de Moradores), política (SEMAP, REARO, SEMUSOP) e mistas (Petrobras) é bem articulada e ativa nas questões ambientais, sendo referência para todo o Estado, segundo Oliveira (2008), promovendo inúmeros eventos e projetos para a população, em uma tentativa de formar uma sociedade consciente com suas obrigações na organização de uma cidade mais limpa e com seus ambientes naturais protegidos.

Um dos fatos que mais atrai pesquisadores no estudo das promulgações feitas pela Constituição Federal de 1988 para aumentar a participação civil nas atividades políticas, são as diversas distorções encontradas em espaços (Conselhos Populares, Conselhos Gestores, Conselhos de Acompanhamento e Controle Social) realizadas pelos administradores políticos para manipular a população, que ludibriada pela falsa ideia de que está participando, acaba por perder o entusiasmo de tomar parte das decisões políticas que afetam suas vidas (GONH, 2001).

Esse fato é recorrente em muitos municípios brasileiros, onde o objetivo principal da criação do CMMA é esconder arranjos políticos e privados com fins econômicos, usando o CMMA como "fachada" para estas atividades. Outros CMMAs não possuem conhecimento técnico para deliberarem sobre os assuntos levados ao seu conhecimento, como no caso do CMMA de Angra dos Reis no Rio de Janeiro (TOLEDO, 2007), que teve de pedir auxílio ao Conselho Estadual para resolver o problema. E que também existem CMMAs que só são formados para obedecer o previsto em Lei, não tendo reuniões freqüentes, estrutura física, nem documentação necessária para funcionar.

Todas estas informações apontavam que estes espaços perderam seus significados e que o projeto pretendido pela Constituição fora mera utopia,

Revbea, Rio Grande, V. 8, № 2:77-92, 2013. 
não se configurando em um benefício para descentralizar a gestão ambiental e dar maior poder e autonomia aos municípios e aumentar a transparência das atividades políticas e promover a educação ambiental, no entanto, outros casos mostraram que quando existe vontade política e organização civil, o quadro muda.

O município de Rio das Ostras foi um exemplo que apresentou grande parte dos requisitos necessários para ser considerado um bom exemplo de união dos segmentos políticos, privados e sociais na formação de um projeto integrado em prol de uma consciência ambiental para a população. Com grande estrutura física, boa parte proporcionada pelos royalties e pelos convênios, tem conseguido gerenciar seus recursos aplicando-os em muitos projetos de educação ambiental e no planejamento urbano, caso considerado o maior degradador dos ambientes naturais do município. Possui uma intrínseca rede de participantes na promoção dos seus projetos ambientais, em conjunto com a Petrobras (Projeto Pólen) na região e com outros municípios, participando em Comitês de Bacias Hidrográficas, entre outros.

\section{REFERÊNCIAS}

BRASIL. Lei $n$. $=6.938$, de 31 de outubro de 1981. Dispõe sobre a Política Nacional do Meio Ambiente, seus fins e mecanismos de formulação e aplicação, e dá outras providências. Diário Oficial [da] República Federativa do Brasil, Brasília, DF, 02 set. 1981.

BRASIL, Lei no 9.795, de 27 de abril de 1999. Que institui a Política Nacional de Educação Ambiental, e dá outras providências. Diário Oficial [da] República Federativa do Brasil, Brasília, DF, 28 abr. 1999.

FARIAS, S.C.G.F. A gestão ambiental descentralizada e participativa: um estudo sobre o conselho municipal de meio ambiente de Rio das Ostras - RJ. 2010. 184 f. Dissertação (Mestrado em Educação) - UNESA, RJ.

GOHN, M.G. Conselhos gestores e participação sóciopolítica. São Paulo: Cortez, 2001.

GOHN, M.G. Protagonismo da sociedade civil: movimentos sociais, ONGs e redes solidárias. São Paulo: Cortez, 2005.

GUIMARÃES, M. Armadilha paradigmática na educação ambiental. In: LOUREIRO, C.F.B.; LAYRARGUES, P.P.; CASTRO, R.S. de (Orgs.). Pensamento complexo, dialética e educação ambiental. São Paulo: Cortez, 2006.

LOUREIRO, C.F.B. et al. Sociedade e meio ambiente: a educação ambiental em debate. $5^{\text {a }}$ ed. São Paulo: Cortez, 2008.

NOVICKI, V. Diagnóstico SocioCulturalAmbiental. Rio de Janeiro, 2006. Disponível em: <http://www.educacaoambiental.pro.br>. Acesso em: 12 jun 2010. 
OLIVEIRA, A.C. Democratização do processo decisório em municípios beneficiários dos royalties petrolíferos: a experiência de Rio das Ostras. 2008. 167f. Dissertação (Mestrado em Engenharia Ambiental) - CEFET, Campos dos Goytacazes.

PEDRINI, A.G. et al. Educação Ambiental: reflexões e práticas contemporâneas. Petrópolis: Vozes, 1997.

RIO DAS OSTRAS. Lei Orgânica do Município de Rio das Ostras, 09 de junho de 1994. Institui a Lei Orgânica de Rio das Ostras.

RIO DAS OSTRAS. Lei Municipal complementar no. 005/2008. Institui o Código de Meio Ambiente do Município de Rio das Ostras, estabelece normas gerais para a administração da qualidade ambiental em seu território.

SANTOS, M.R.M. Conselhos Municipais: a participação cívica na gestão das políticas públicas. 2000. 138 p. Dissertação (Mestrado em Planejamento Urbano) - UFRJ, Rio de Janeiro.

SOUZA, D.B. Acompanhamento e controle social das políticas públicas ambientais: um estudo sobre os Conselhos Municipais de Meio Ambiente no Estado do Rio de Janeiro. Rio de Janeiro: UNESA, 2008. (mimeo)

SOUZA, D.B. et al. Desafios da Educação Municipal. Rio de Janeiro: DP\&A, 2003.

TOLEDO, R.A. Capacidade e sustentabilidade da gestão ambiental municipal: proposta de um sistema de indicadores e a avaliação do Município de Angra dos Reis - RJ. 2007. 175 f. Dissertação (Mestrado em Ciência Ambiental), UFF, Niterói.

VECCHIA, R. Descentralização e controle da administração pública nos municípios brasileiros depois da Constituição de 1988. Belo Horizonte: Anais CONPEDI, 2006. 